\title{
Feminism in Susie Chao's Sai Jinhua
}

\author{
Xin $\mathrm{Li}$ \\ School of Literature \\ Capital Normal University \\ Beijing, China
}

\begin{abstract}
Sai Jinhua is a controversial female for her impact on the history of late Qing and Early Republican China. From late Qing Dynasty till now, there are continuous research and literary creation on Sai Jinhua. Susie Chao, a Swiss of Chinese ancestry writer, creates the novel Sai Jinhua from the perspective of a female writer who lives abroad for a long time. She makes detailed description of Sai Jinhua's controversial life experience. This paper takes the novel Sai Jinhua as the analysis object, and believes that through describing the survival, awakening and resistance of prostitute group represented by Sai Jinhua during the historical development process, the author not only shows the readers the impact of social custom of the time on female development objectively, but also provides brand new view for understanding and evaluating the historical figure, Sai Jinhua. The character image of Sai Jinhua in the works of the writer is the historical figure under Chinese cultural background; meanwhile, it is also the flag with western women's sense of independence and feminism thought.
\end{abstract}

Keywords-Sai Jinhua; women's sense of independence; feminism

\section{INTRODUCTION}

Sai Jinhua is a controversial female for her impact on the history of late Qing and Early Republican China. Her whole life not only reflects her tragic fate, but also becomes epitome of female existence in Chinese modern society development. From late Qing Dynasty till now, there are continuous research and literary creation on Sai Jinhua. Among numerous creations which take Sai Jinhua as theme, Susie Chao, a Swiss of Chinese ancestry writer, creates a novel Sai Jinhua from the perspective of a female writer who lives abroad for long term, and makes detailed description of Sai Jinhua's controversial life experience. Late Qing period was a historical period with rapid change of social system. The females in this period lived in an environment of numbers of constraints as well as reformation. No matter on the appearance or inner heart, the female experienced new metamorphosis in spite of quite difficult process. In traditional feudal concepts, it has typical requirement on women's beauty, represented by two major social customs of "Footbinding" and "Less education". Women experienced double destruction physically and mentally. As a female representative in this period, Sai Jinhua's life experience exactly reflects the awakening of women's independent consciousness and resistance to patriarchal society in the period of historical change.

\section{IMPACT OF FOOTBINDING ON PRODUCTIVITY DEVELOPMENT}

There had been a long history of women's footbinding custom in ancient China. Up to now, there are many explanations about its origin in historian circle. However, there is an indisputable fact that "women's footbinding custom developed and expanded quickly since it occurred in Northern Song Dynasty. It was intensified and reached its peak development in the period of Ming and Qing Dynasty. The footbinding custom spread from Northern to the Southern China and transferred from local phenomenon to common phenomenon gradually. Women's feet were bound from big to small and became more and more slim. Meanwhile, the feet changed from original straight shape to arcuate curve shape. [1]" Footbinding, as a special phenomenon in the history of Chinese culture, is one of the keywords which reflect the daily life of Chinese women. In the novel, the writer uses considerable descriptions to reflect this ancient social phenomenon by the main character in the novel.

"Do you want to be an ugly girl? Have you ever seen a lady with two big feet? [2]" Starting with her mother's words, Sai Jinhua began her footbinding life. In ancient Chinese society, women with big feet were defined as "ugly". To regard small feet as beauty was not only a social custom, but also a symbol of female beauty. The criterion for making Sai Jinhua a famous prostitute in the late Qing Dynasty, apart from her good looks, was her Three-inch Golden Lotus. In the novel, the writer uses the words of Hong Jun, Sai Jinhua's first husband, to reflect that men's common aesthetic requirements for women in this period were "small feet are beautiful. Western woman with those two big feet are like a man. It is really scary! I love your little three-inch golden lotus. [2]" In the patriarchal society of ancient China, men's aesthetic orientation was the dominant orientation. The love of small feet was considered as a normal aesthetic orientation. The special social phenomenon of "The worship of Golden Lotus" even appeared. "In the peak period of footbinding, it was success ladder for women. Thus, it also reflected men's fate in the face of the imperial examinations: imperial examination was their ladder for entering officialdom. However, the competition became incredible severe when more and more people participated in the arena. In this situation, there was a popular view in the society that the winners and losers were predestined rather than the result of hard work or laziness. The fatalism mitigated the stigma 
of failure and continued to support the increasingly absurd system and reputation, and further seduced more and more people into the competition. [3]" Comparing women's footbinding with imperial examination system in feudal age, the social environment made the women to yield to this unwritten collective identity idea. The behavior of women's footbinding became the competition between each other, just like the winner in imperial examination system, "a pair of beautiful feet of woman was higher than all aesthetic standards; while the detailed level of small feet was higher than the judgment of women's looks. [4]"

In addition to aesthetic factor, the reason of footbinding was mainly to restrict women's actions. This inevitably leads to economic dependence on men. As the folk song goes, "wrap your feet, wrap your feet, you are not allowed to work outside the gate", which shows the limitation of women's action due to footbinding. Due to the limitation of action, women were trapped in their families and unable to participate in social labor, which inevitably led to the decline of social productivity. Qian Yong in Qing Dynasty once said: "women's footbinding will lead to their own various diseases; when a woman is ill, her children must be equally ill; when offspring are weak and ill, then everything in the world will collapse![5]" Women's footbinding not only caused double harm to the body and soul of women, but also directly caused part of social labor force deficiency due to the limitation of action after footbinding, which resulted in the decrease of social productivity at that time.

However, after a long period of anti-footbinding movement, the social phenomenon of women's footbinding finally came to an end in 1930s and 1940s. Another kind of shackle to women's feet, i.e. high heels, came to the forefront from the corner of history on aesthetic ground. According to many traditional views, high heels were introduced into China from the western countries before and after the revolution of 1911 in modern China. However, during the exploration of ancient Chinese shoe culture, although the aesthetic standards of the birth of high heels in China and the western countries were different, both of them appeared in the male-dominated society for the purpose of female physical beauty. The decorations like high heels were called as "Chopine" in early China. Its history and the history of women's footbinding in China were almost at the same period, taking its developing stage for example, "hulvplatform shoes" in Spring and Autumn Period and the Warring States Period, "round-toe clogs" in Wei Jin and the Northern and Southern Dynasties, "princess shoes" in Sui Tang and the Five Dynasties, "silk clogs" in Song and Yuan Dynasties, "horseshoe-soled shoes" and "saucers shoes" of Manchu in Ming and Qing Dynasties. In China, high heels and footbinding are complementary aesthetic standards to evaluate a woman's beauty. The difference is that footbinding disappeared in the ceaseless resistance movement of modern and contemporary history, while high heels develop with swift and violent trend till today and become the aesthetic standard for modern, and fashionable new woman. In the novel, the writer also mentions this socalled "Chopine". Sai Jinhua accompanies her husband to foreign country. At her first party, Sai Jinhua wears the formal dress as the wife of Zhuangyuan (the person who win the first place in the imperial examination), and elaborate Palace Shoes. "The heelpiece of the Palace Shoes is made by a skillful worker. It contains a powder package which is mixed with osmanthus powder and cardamom powder. A pink print will be on the marble floor when the person takes one step. It is really beautiful and peerless. [2]" The above mentioned "Palace Shoes" is a popular "Chopine" in Qing Dynasty. By the description that people made painstaking efforts to design such chopine, it shows women's preference for chopine at that time. This kind of shoe that was believed to add female glamour, actually, is just like footbinding which achieves beauty by hurting female body. By wearing high heels, it can make abdomen and hip tighten so that the pace and posture is light and slender, but it transfers body center of gravity forward and makes the toes overload which make the foot moves forward in the front of the shoe. In fact, it is "footbinding" in other form. If woman wears it for long time, it will cause a variety of foot diseases. Therefore, high heels are endowed with the name of "three-inch golden lotus" in modern society. The development from footbinding to high heels culture nowadays reflects the transformation of old and new culture concept in modern China. Whereas, the aesthetic demand of patriarchal society still exists. Women are still in the form of hurting their own body to satisfy men's aesthetic demand (although most modern women consider that they wear high heels for improving their own charm rather than please men).

It is worth noting that the impact of women on the productivity development has been different from footbinding in ancient society to high heels culture in modern society. In the ancient imperial society, women's footbinding limited their range of activities greatly. It made them restrict in their boudoir and lose the interaction between themselves and the society. As a result, it hindered the development of the social productivity at that time. However, in the modern commodity economy society, women's high heels culture drives the development of modern consumer market (women's shoes and boots product market, and even luxury market); and becomes one of the driving forces of social development productivity. Events of the same nature have difference impacts on the development of productive forces in different times. This paradoxical result is not only a manifestation of the transformation of old and new cultural concepts in China, but also a reflection of the transformation of factors which influence the development of productive forces in different times.

\section{IMPACT OF "LESS EDUCATION IS A VIRTUE FOR WOMEN" CONCEPT ON FEMALE DEVELOPMENT}

The saying "Less education is a virtue for women" appeared in the late Ming Dynasty. It highly summarizes the standard norms on women's "talent" and "virtue" in feudal society. The ancient Chinese people always valued ability and virtue. In the History as Mirror, it describes as follows, "the person who has talent and virtue is perfect person; the person who neither has talent nor virtue is stupid person; the person whose virtue is higher than his talent is superior man; the person whose talent is higher than his virtue is servants." 
It reflects that the requirements for virtue were stricter than the value of individual talent in the eyes of ancient Chinese people, especially for women. For women, the so-called "talent" does not mean wisdom, but simply know the meaning of Chinese characters. Therefore, the answer to the riddle "less education is a virtue for women" is that women who know the meaning of Chinese characters are disgusting and salacious. This kind of idea reached its peak period in the Ming and Qing Dynasties. In the patriarchal society, women's so-called talent was often associated with the words like obscene, dissolute, and immoral.

However, western feminist thoughts were introduced into China after the opium war. Women began to rethink themselves and the society, especially the rebellion against the relationship between "less education for women" and "virtue". In the novel, the writer takes Sai Jinhua as the rebel image of this concept. On the journey of Sai Jinhua to the foreign country with her husband, the writer makes up such a plot: Sai Jinhua's husband, Hong Jun, often taught her to recite poems on the journey to overseas. Nevertheless, his behavior is only because of his love for her, to kill time. In fact, he still holds the idea that less education is a virtue for women. He thinks that learning is "immoral" and boring for women, and it is an act that will cause others to laugh at him. However, Sai Jinhua is eager to learn. In her eyes, only when a woman keeps learning, she can adapt herself to the new environment. The learning consciousness of Sai Jinhua which is described and emphasized by the writer is not only reflected in her independent learning of language, but also in her leaning of western life and behavior habits. For example, at the dinner party held in the Chinese embassy, Sai Jinhua combines the difference of Chinese and western eating habits, "the menu is quite elaborate, both exquisite and catering to the appetite of western guests, but not too fragmented [2]" "the dishes shall be laid out beautifully, because westerners value this point and mention 'be artistic'[2]". The success of the banquet is the result of Sai Jinhua's deep learning and understanding of western culture.

In the writer's works, the most prominent rebellious expression of Sai Jinhua is the emergence of her female independence consciousness. "It is my own life, and I can do what I want to! [2]" This is the inner cry of Sai Jinhua; in the meantime, it is also the call of writer for awakening women's consciousness. She wants to be a real person rather than a doll that attach to someone else's existence. The writer's description of Sai Jinhua's performance for rescuing the citizens of Beijing during the opium war is exactly the publicity of the theme of "prostitute saves the country". According to The Morning Post of Beijing at the time of her death (8 December 1936): "people from all walks of life in Beijing thank Sai Jinhua for her contribution in war, and seek to help her... Sai Jinhua, a famous prostitute, was patriotic and sympathetic to the people at the moment of national survival during the opium war. She did not hesitate to sacrifice herself to maintain the temporary safety of millions of people." In addition, some literati celebrities in the late Qing Dynasty also wrote about the righteous acts of Sai Jinhua in this period.
At the same time, in order to perfect the image of leading character, the writer also makes up some plots about the war. In the novel, Sai Jinhua persuades German marshal Alfred Graf Von Waldersee to restrain his soldiers. Her trenchant talk is not only logically clear, but also full of national integrity. In China at that time, women's consciousness of self-independence and national consciousness was gradually awakened. This kind of awakening was even reflected in the special social groups represented by Sai Jinhua. During the May 4th movement, prostitutes in Shanghai organized spontaneous protests. A statement which was issued at that time by prostitutes said, "Our China has come to the point about to die. China is not dead yet because our people still retain a little national spirit... It can be seen that people's hearts are immortal, which is the glimmer of vitality of our country. Only my brothel did not do anything. In my conscience, I have devised several measures to advise my fellow prostitutes to do their duty as citizens and follow your own conscience." It shows that there was no shortage of patriotic person among prostitutes in this period. In addition, the writer also describes the story of prostitutes who sacrifice themselves in the novel. These prostitute girls are willing to sacrifice their lives in order to save their compatriots. This farewell of sacrificing themselves and going to help save the country from danger is not only the awakening of humanistic spirit, but also the cry of female consciousness which had been oppressed by patriarchal society and imperial society for thousands of years.

\section{CONCLUSION}

Taking the society of late Qing Dynasty as the stage, the writer describes the survival, awakening and resistance of prostitute groups represented by Sai Jinhua in the historical flood; and plays scenes of human tragicomedy. The writer has deep understanding of Chinese history and western culture, and integrates her self-consciousness into the shaping of character features and destiny. The character image of Sai Jinhua has become a typical way for the writer to blend Chinese and western writing techniques. She is not only a historical figure under Chinese culture background, but also a symbol which is infused with western women's independent consciousness and feminist thoughts. We can say that this image is the historical existence of the figure; meanwhile, it is also the product of the writer's selfconsciousness. By creating such a figure image, the writer not only objectively shows the readers the influence of social customs on the development of woman at that time, but also provides a new perspective for the understanding and evaluation of Sai Jinhua, a historical figure.

\section{REFERENCES}

[1] Hongxing Gao, The History of Footbinding, Shanghai: Shanghai Literature and Art Publishing House, 1995. (in Chinese)

[2] Susie Chao, Sai Jinhua, Nanjing: Jiangsu Literature and Art Publishing House, 2010. (in Chinese)

[3] Ko. Dorothy, Cinderella's Sisters: A Revisionist History Of Footbinding. Berkeley: University Of California Press, 2005.

[4] Guanglian Geng, Changes in Social Customs and Modern China, Jinan: Publishing House of Jinan, 2010. (in Chinese) 
[5] Yong Qian, Caterpillar Garden, Beijing: Zhonghua Book Company, 1979. (in Chinese)

[6] Dongyuan Chen, Chinese Women's Life History, Beijing: The Commercial Press, 1998. (in Chinese)

[7] Gail Hershatter, Dangerous pleasures: prostitution and modernity in twentieth-century Shanghai, Berkeley: University of California Press, 1997.

[8] McAleavy Henry, That Chinese woman: The life of Sai-Chin-hua, New York: Thomas Crowell Co., 1959. 